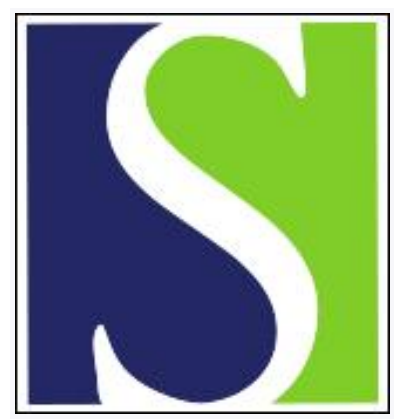

Scand J Work Environ Health Online-first -article

https://doi.org/10.5271/sjweh.2912

Published online: 29 Mar 2010

The natural course of carpal tunnel syndrome in a working population

by Silverstein BA, Fan ZJ, Bonauto DK, Bao S, Smith CK, Howard N, Viikari-Juntura $\mathrm{E}$

Affiliation: Safety \& Health Assessment and Research for Prevention (SHARP), Washington State Department of Labor \& Industries, PO Box 44330, Olympia, Washington 98504-4330, USA. silb235@Ini.wa.gov

Refers to the following texts of the Journal: 2006;32(2):99-108 2009;35(2):113-126 2001;27 suppl 1:1-102 2009;35(1):19-36

The following articles refer to this text: $2011 ; 37(2): 81-84$; 2013;39(5):495-505

Key terms: active worker; carpal tunnel syndrome; CTS; incidence; nerve entrapment; persistence; physical load factor; prevalence; psychosocial factor; working population

This article in PubMed: www.ncbi.nlm.nih.gov/pubmed/20352175 


\title{
The natural course of carpal tunnel syndrome in a working population
}

\author{
by Barbara A Silverstein, PhD, MPH, ${ }^{1}$ Z Joyce Fan, PhD, ' Dave K Bonauto, MD, MPH, ${ }^{1}$ Stephen Bao, PhD, ${ }^{1}$ \\ Caroline K Smith, MPH, ${ }^{1}$ Ninica Howard, MSc, ${ }^{1}$ Eira Viikari-Juntura, DMedSci, PhD ${ }^{2}$
}

\begin{abstract}
Silverstein BA, Fan ZJ, Bonauto DK, Bao S, Smith CK, Howard N, Viikari-Juntura E. The natural course of carpal tunnel syndrome in a working population. Scand J Work Environ Health. 2010;36(5):384-393.

Objective The aim of this study was to assess prevalence, incidence, and persistence of carpal tunnel syndrome (CTS) and associated symptoms over a one-year period in a working population.

Methods We conducted a one-year prospective study of 418 active workers in 12 worksites. Detailed health interviews, psychosocial questionnaires, and electrophysiological studies [ie, nerve conduction velocity (NCV) tests] were conducted at baseline and one-year follow-up. Individual-observed exposure assessments of wrist posture, hand activity, and hand forces were conducted.
\end{abstract}

Results Prevalence of CTS cases at baseline was 10.8\% [95\% confidence interval (95\% CI) $7.8-13.7 \%$ on the dominant side and $6.0 \%(95 \%$ CI $3.7-87.3 \%)$ on the non-dominant side; CTS symptoms were $14.1 \%(95 \%$ CI $10.8-17.5 \%)$ and $11.0 \%$ (95\% CI 8.0-14.0\%), respectively. Incidence of CTS cases were 7.5\% (95\% CI $4.8-10.2 \%)$ and $5.6 \%$ (95\% CI 3.3-7.9\%), respectively. Higher proportions of subjects with current symptoms or positive electrophysiological test findings at baseline became CTS cases at one year compared to those with neither $(28.6 \%$ and $13.9 \%$, respectively, versus $0.5 \%)$. One-year persistence of CTS case status was $44.4 \%$ (95\% CI 29.9-59.0\%) for the dominant hand and 52.0\% (95\% CI 32.4-71.6) for the non-dominant hand. There were significant differences at baseline between asymptomatic subjects and CTS cases with respect to higher job demands $(\mathrm{P}=0.027)$, lower job satisfaction $(\mathrm{P}=0.036)$, lower general health $(\mathrm{P}=0.0009)$, higher exposure to vibrating hand tool use $(\mathrm{P}=0.039)$, and greater time using a forceful power grip $(\mathrm{P}=0.035)$ among cases.

Conclusions CTS symptoms more than positive NCV test results alone appear to predict CTS at one year. Persistence of CTS at one year is high.

Key terms active worker; incidence; nerve entrapment; persistence; physical load factor; psychosocial factor; prevalence; CTS.

Carpal tunnel syndrome (CTS) is the most common upper-extremity peripheral neuropathy. Carpal tunnel release is the most commonly performed surgery of the hand with estimates of up to 500000 cases per year in the United States (1). Prevalence of CTS has been estimated at $3.8 \%$ in the general Finnish population and the disease is 2.5 times more common among women than men (2). The incidence of reported CTS in the general population of Olmstead County, Minnesota, from 2000 2005 was 4.4 per 10000 and the average incidence of work-related CTS surgery was 1.1 per 10000 (3). The prevalence of electrodiagnostically confirmed CTS from employee computer use and among active workers in healthcare and construction was $1.7 \%$ (4). The incidence of CTS confirmed with nerve conduction studies in the general Dutch and Italian populations varied between $1.8-2.8$ per 1000 in $2001(5,6)$.

Work-related neck, back, and upper-extremity musculoskeletal disorders (MSD) represent $27 \%$ of all workers' compensation claims in Washington State, $36 \%$ of claims resulting in $\geq 4$ lost work days, and more than $43 \%$ of all costs (7). CTS accounts for $2 \%$ of all workers' compensation claims, $5 \%$ of all costs, and 2.7 times the median lost workdays (93 versus 34) for all claimants. CTS claimants are more likely to be female (58.8\% versus $32.7 \%$ for all claimants), overweight (average body mass index 28.3 versus 27.2), and on the job of injury longer (31 months versus 12 months) than

1 Safety \& Health Assessment and Research for Prevention (SHARP), Washington State Department of Labor \& Industries, Olympia, Washington, United States.

2 Finnish Institute of Occupational Health, Helsinki, Finland.

Correspondence to: Dr B Silverstein, Safety \& Health Assessment and Research for Prevention (SHARP), Washington State Department of Labor \& Industries, PO Box 44330, Olympia, Washington 98504-4330, USA. [E-mail: silb235@1ni.wa.gov] 
non-claimants (7). Long-term earnings losses for CTS claimants, measured seven years post-claim filing, are much greater for male than female CTS claimants, after adjusting for age, industry, and geography (8).

Work-related CTS has been associated with high hand forces (forceful pinch or power grip) often in combination with highly repetitive movements, and hand-arm vibration (9).

Because the incidence and costs of hand-wrist disorders are high, a better understanding of the natural course of these disorders in an active working population can help target both primary and secondary prevention efforts. The aims of this study were to (i) assess prevalence, incidence, and persistence rates of CTS and hand-wrist symptoms over a one-year period in a working population, and (ii) study whether hand-wrist symptoms and nerve conduction study (NCV) findings alone predict clinical case status of CTS.

\section{Methods}

\section{Design}

We conducted a prospective cohort study of CTS and hand-wrist symptoms among full-time employees in 11 different manufacturing and healthcare facilities in the State of Washington from 2001-2005. Ergonomists performed a workplace walk-through to categorize jobs according to the American Conference of Governmental Industrial Hygienists (ACGIH) threshold limit value for hand-activity level (10). Facilities with $\geq 20$ employees in $\geq 3$ of 6 hand force (high/low) by repetition (high/medium/low) categories were eligible for inclusion. Those eligible and willing to participate in health assessment data collections completed an informed consent form approved by the Washington State Institutional Review Board and entered into baseline data collection.

At baseline and one-year follow-up visits, we collected information on each individual's work and health assessment with appropriate blinding between interviewers, examiners, and ergonomists. If a change in job was reported, job tasks were re-evaluated. Exclusion criteria included working: (i) part-time or with temporary status, (ii) in mobile jobs such as forklift drivers, (iii) in jobs with $\geq 4$ tasks due to resource constraints. The health team (physician, nurse, and physical therapist) conducted the individual health assessment during work hours and was blinded to exposure category and health history. Two certified electrodiagnostic technicians conducted baseline and follow-up median motor and sensory nerve and ulnar sensory nerve function tests at the wrist.

\section{Subjects}

The majority of the participants $(86.5 \%)$ worked in the manufacturing sector (electronics, medical or exercise equipment, windows, kitchen cabinets, wood mills). At baseline, 733 subjects ( $64.5 \%$ of those eligible) participated in the study. The reasons for non-participation were mostly related to the production process (eg, not being allowed time off the job to participate). At baseline, 720 subjects completed electrophysiological testing. We excluded 29 subjects who reported that their hand-wrist problem started as the result of a sudden injury (13 on the right, 13 on the left, 3 on both sides), leaving 691 subjects in the study.

At one-year follow-up, 418 (58.1\% of those at baseline) were available for the study. Many of those lost to follow-up were laid off (23.7\%) or had employment terminated (26.3\%) during the economic recession, while $5.3 \%$ of the participants had left the company for another job and $9.5 \%$ were no longer interested in participating. The remaining participants were unavailable due to vacation, sick leave, or an unknown reason. Two subjects $(0.8 \%)$ were deceased. While those lost to follow-up had higher overall psychosocial strain at baseline, there were no significant differences in baseline standard form $12(\mathrm{SF}-12)$ (11) scores for mental $(\mathrm{P}=0.86)$ or physical $(\mathrm{P}=0.07)$ health between those lost to follow-up and those who remained in the study. A review of workers' compensation data did not show that a larger portion of those lost to follow-up filed workers compensation claims than those remaining at the workplace.

\section{Health assessment}

Trained interviewers collected information on individual factors (age, gender, race, and education), a detailed structured health history (smoking history, current pregnancy, birth control or estrogen replacement pill use, conditions diagnosed by medical doctor including diabetes, hypertension, gout, thyroid condition, rheumatoid or osteoarthritis, thoracic outlet syndrome, CTS, and fractured wrist), sports and hobbies [such as racket sports, gardening or knitting (frequency)], job history (current job, time on job, and change in jobs), and the presence of musculoskeletal symptoms. Hobbies and sports were classified into those with high hand force or repetitiveness demands. The subjects were queried about symptoms (using a body map) of any pain or discomfort in the previous 12 months that lasted $\geq 1$ week or occurred $>3$ times. For subjects with pain or discomfort, a specific body map, and hand diagram were used to ascertain a more precise location of symptoms. Information was also obtained on onset, duration, frequency, severity, last occurrence, and treatment of pain, and whether there 
was interference with work pace or quality and number of lost workdays. Those with upper-extremity symptoms in the past week completed the QuickDASH (11) as an estimate of upper-extremity disability. Interpreters were available to assist those whose primary language was not English.

The subjects completed a self-administered psychosocial questionnaire, which included the SF-12 (12), job demands, decision latitude, job security, job satisfaction $(13,14)$, and social support (14). The questionnaire was available in multiple languages. Assistance was provided for subjects with reading difficulties.

A brief physical examination of the neck and upper extremity was conducted according to Suiter et al (15). Height, weight, wrist width, and wrist depth were measured to calculate the body mass index and wrist ratio. Pinch and power grip strength were also measured during the physical examination.

The two certified electrodiagnostic technicians, who were blinded to job information, conducted all NCV tests performed on the dominant hand using standard techniques of supramaximal percutaneous nerve stimulation and surface recording with a Cadwell Sierra II Wedge (Cadwell Laboratories Inc, Kennewick, Washington, USA) electrodiagnostic machine. Anatomic landmarks and standardized stimulation to recording electrode distances are shown in table 1. While measuring locations for electrode placement, the wrist is held straight with the fingers extended. Skin temperature was measured using an Electromedics digital skin thermometer. The hand was wrapped in an electric heating pad if necessary to obtain a digital temperature of greater than $32^{\circ} \mathrm{C}$. Criteria for median neuropathy at the wrist (consistent with CTS) include: (i) median motor latency at $8 \mathrm{~cm}>4.5 \mathrm{msec}$, median sensory latency D2-wrist at $14 \mathrm{~cm}>3.5 \mathrm{msec}$, or mid-palmer latency at $8 \mathrm{~cm}>2.2 \mathrm{msec}$; and (ii) ulnar sensory latency at $14 \mathrm{~cm}<3.7 \mathrm{msec}$; or (iii) median sensory latency at $14 \mathrm{~cm}$ minus ulnar sensory latency $>0.5 \mathrm{msec}$ or mid-palmar difference $>0.3$ msec.

Complete ulnar nerve studies were not done as part of

Table 1. Anatomic landmarks and distance between stimulating and recording electrodes. [S=sensory; $\mathrm{M}=$ motor nerve.]

\begin{tabular}{lllc}
\hline Nerve & Recording electrode & Stimulate & $\begin{array}{c}\text { Distance } \\
(\mathrm{cm})\end{array}$ \\
\hline Median S & $\begin{array}{l}\text { Digit II, proximal \& distal } \\
\text { phalanxes; 3-4 cm apart }\end{array}$ & Wrist & 14 \\
Median S & $\begin{array}{l}\text { Wrist, between palmaris } \\
\text { longus \& flexor carpi } \\
\text { radialis tendons }\end{array}$ & $\begin{array}{l}\text { Mid palm } \\
\text { Mid thenar crease }\end{array}$ & 8 \\
Median M & $\begin{array}{l}\text { Thenar abductor pollicis } \\
\text { brevis muscle } \\
\text { Digit V, proximal \& distal } \\
\text { phalanxes; 3-4 cm apart } \\
\text { Ulnar S }\end{array}$ & Wrist & 8 \\
Ulnar S & Medial Wrist & Medial palm & 8 \\
\hline
\end{tabular}

the research protocol. Dr Gary Franklin, a Board-certified neurologist and Medical Director for the Washington State Department of Labor and Industries, reviewed all final protocols and methods for the electrodiagnostic testing. He also reviewed all the individual results.

Symptoms, NCV findings, and job exposure data were collected at baseline and one year. Subjects were provided with the results of their NCV tests with an interpretation of their meaning and a telephone number to call if they had questions.

\section{Case definitions}

To be classified as being a CTS case, the subjects had to meet both of the following criteria: (i) experience pain, numbness, tingling, or burning in $\geq 1$ of the first 3 digits (equivalent to Katz criteria for possible CTS) in the past 12 months occurring $>3$ times or lasting $>1$ week, with no acute traumatic onset; and (ii) meet nerve conduction study criteria for abnormal nerve conduction test, which included either delayed median motor latency, delayed sensory distal latency, or median-sensory latency difference as described above.

With the permission of the subjects, individual claims data were extracted from the workers' compensation system for evidence of non-traumatic hand wrist disorders between 2000-2003 to compare with the findings of the study case definition.

\section{Physical exposure assessment}

Ergonomists were blinded to the health status of the participants. In order to assure variability in exposure, we used the ACGIH hand activity level (10) on workplace walkthrough to categorize subjects into six preliminary exposure categories. A detailed description of the exposure assessment methods are reported elsewhere $(16,17)$.

Individual exposure assessment included the use of two synchronized cameras videotaping tasks to quantify exposures to forceful exertions, postures, and repetitive movement. The ergonomist measured at task level any high forces perceived to be $\geq 8.9 \mathrm{~N}$ of pinch or object weight (corresponding to $2 \mathrm{lb}$ or $0.9 \mathrm{~kg}$ ), or $44.1 \mathrm{~N}$ of power grip, object weight, or push/pull force (corresponding to $10 \mathrm{lb}$ or $4.5 \mathrm{~kg}$ ). Videotapes of the tasks were time-studied using the Multimedia Media Task Analysis (MTVA) software (18). The frequency and duration of each forceful exertion were computed. Task distribution information (\% time each task took in the job) was obtained via an interview with the workers or their supervisors. These were used to develop timeweighted estimates for each task and translated into the percentage of the shift with forceful exertions for the left and right hand, and frequency of forceful exertion per 
minute over all tasks. The calculation of the percentage of the shift for the various forceful exertions was done for pinch grip, power grip, and lifting. Since all of these variables showed a highly skewed distribution, and some of our diagnostic groups were small, we dichotomized the variables according to published guideline limits, as in appendix B of the Washington State ergonomics guidelines (19). The cut-off points for high frequency of high-force exertions or posture durations were close to the $75^{\text {th }}$ percentile value of these exposure variables. Vibrating tool use was binary (yes/no). We recorded the time of use, but no vibration measurements were recorded.

\section{Analysis}

Because the focus of this paper is to show the clinical course of non-traumatic hand-wrist symptoms and CTS in working populations, descriptive statistics are presented by wrist and clinical category. Psychosocial factors were dichotomized based on median scores. Analyses were conducted using version 9.1 of SAS statistical software (SAS Institute, Cary, NC, USA). The Kruskal-Wallis test was used to assess differences between clinical categories for continuous variables and Chi-square tests were used for categorical variables.

\section{Results}

Demographic characteristics, physical exposure, and psychosocial factors by hand-wrist status at baseline

Of the 691 subjects participating at baseline, $51.7 \%$ were male, $58.9 \%$ were white, followed by $18.9 \%$ Asian; $83.5 \%$ had at least a high school education. The median age was 40.1 years and subjects were a 2.4 median years on the job. Those lost to follow-up ( $\mathrm{N}=273)$ tended to be male $(57.5 \%)$, white $(62.3 \%)$, younger (median age 37.6 years), and spent less time on the job (median 1.9 years).

To follow the natural course, we classified the subjects into four categories according to symptoms and findings from the NCV testing (table 2). For analysis purposes, we combined those with past $(\mathrm{N}=3)$ and current $(\mathrm{N}=14)$ symptoms. For conciseness of presentation, the results focus primarily on the dominant hand. Of the 418 baseline participants available at the one-year follow-up, a greater proportion of female participants reported symptoms and were classified as CTS cases than men $(\mathrm{P}<0.02)$. Men had a slightly higher percentage with a combination of positive NCV result and no reported symptoms than with symptoms or CTS case status alone. Asian subjects reported fewer past or

Table 2. Demographic and health characteristics of the subjects by dominant hand status at baseline ( $N=418)$. [NCV=nerve conduction velocity; CTS=carpal tunnel syndrome.]

\begin{tabular}{|c|c|c|c|c|c|c|c|c|c|c|c|}
\hline \multirow[t]{2}{*}{ Characteristic } & \multicolumn{2}{|c|}{$\begin{array}{l}\text { All subjects attending } \\
\text { one year follow-up } \\
(\mathrm{N}=418)\end{array}$} & \multicolumn{2}{|c|}{$\begin{array}{c}\text { No symptoms } \\
\text { and negative NCV } \\
(\mathrm{N}=191)\end{array}$} & \multicolumn{2}{|c|}{$\begin{array}{l}\text { No symptoms } \\
\text { and positive NCV } \\
(\mathrm{N}=165)\end{array}$} & \multicolumn{2}{|c|}{$\begin{array}{l}\text { Past or current } \\
\text { symptoms } \\
(\mathrm{N}=17)\end{array}$} & \multicolumn{2}{|c|}{$\begin{array}{l}\text { CTS cases } \\
(\mathrm{N}=45)\end{array}$} & \multirow[t]{2}{*}{ P-value a } \\
\hline & Mean & $\%$ & Mean & $\%$ & Mean & $\%$ & Mean & $\%$ & Mean & $\%$ & \\
\hline Gender & & & & & & & & & & & 0.0155 \\
\hline Male & $\cdot$ & 47.9 & . & 55.0 & . & 45.5 & . & 35.3 & . & 31.1 & . \\
\hline Female & $\cdot$ & 52.1 & . & 45.0 & . & 54.5 & . & 64.7 & . & 68.9 & . \\
\hline Race & & & & & & & & & & & 0.11 \\
\hline White & . & 56.7 & . & 59.2 & . & 51.5 & . & 76.5 & . & 57.8 & . \\
\hline Asian & . & 19.1 & . & 15.7 & . & 24.9 & . & 0 & . & 20.0 & . \\
\hline Hispanic & . & 14.1 & . & 16.8 & . & 13.3 & . & 11.8 & . & 6.7 & . \\
\hline Other & $\cdot$ & 10.1 & $\cdot$ & 8.4 & $\cdot$ & 10.3 & $\cdot$ & 11.8 & $\cdot$ & 15.6 & $\cdot$ \\
\hline $\begin{array}{l}\text { Education (at least } \\
\text { high school) }\end{array}$ & $\cdot$ & 83.0 & . & 84.8 & $\cdot$ & 80.6 & $\cdot$ & 88.2 & $\cdot$ & 82.2 & 0.69 \\
\hline Age & 40.6 & . & 36.9 & . & 43.6 & $\cdot$ & 35.1 & . & 46.8 & . & $<0.0001$ \\
\hline Body mass index & 27.3 & . & 26.4 & . & 27.8 & . & 28.2 & . & 29.0 & . & 0.0122 \\
\hline Years in current job (median) & 2.6 & . & 2.5 & . & 3.0 & . & 2.4 & . & 3.2 & . & 0.36 \\
\hline Smoking status & & & & & & & & & & & 0.40 \\
\hline Current & . & 31.3 & . & 29.8 & . & 30.9 & . & 47.1 & . & 33.3 & \\
\hline Past & $\cdot$ & 20.3 & . & 18.9 & . & 19.4 & . & 23.5 & . & 28.9 & - \\
\hline Never & $\cdot$ & 48.3 & $\cdot$ & 51.3 & $\cdot$ & 49.7 & $\cdot$ & 29.4 & $\cdot$ & 37.8 & $\cdot$ \\
\hline High blood pressure & $\cdot$ & 15.4 & . & 15.3 & $\cdot$ & 14.6 & $\cdot$ & 17.7 & $\cdot$ & 18.2 & 0.88 \\
\hline Had wrist fracture & $\cdot$ & 5.8 & . & 4.2 & . & 4.9 & . & 17.7 & . & 11.6 & 0.0443 \\
\hline Hobbies with high hand force & $\cdot$ & 39.7 & $\cdot$ & 40.3 & $\cdot$ & 37.6 & $\cdot$ & 47.1 & $\cdot$ & 42.2 & 0.84 \\
\hline Hobbies with high hand repetition & . & 33.3 & . & 35.1 & . & 29.1 & . & 41.2 & . & 37.8 & 0.48 \\
\hline
\end{tabular}

${ }^{a}$ Chi-squared (for gender, education, high blood pressure, wrist fracture, and hobbies of high hand force or repetition) or Fisher's tests (for race and smoking status), Kruskal-Wallis test (years in current job), and ANOVA (age and body mass index). 
current symptoms alone but had a high prevalence of abnormal NCV (24.9\%), which raises a concern about potential under-reporting of symptoms among this population. Hispanic workers had the lowest proportion of CTS cases. CTS cases were older and heavier, and those with symptoms or CTS were more likely to have had a wrist fracture. Those with a history of current or past symptoms were more than twice as likely to have had a wrist fracture in the past. There were no significant differences between groups in terms of participation in hand-intensive sports or hobbies, smoking status, or history of hypertension, diabetes, thyroid disorder, gout, Raynaud's phenomenon, or thoracic outlet syndrome. Four female subjects were pregnant at baseline but had no symptoms or abnormal NCV results. There were no differences for females between groups for either hormone replacement therapy or birth control pill use [23 subjects $(5.5 \%)$ responded positively but there was no difference between diagnosis groups $(\mathrm{P}=0.83)$ ].

There were no significant differences in disability measures (ie, QuickDASH) or treatment between those with past or current symptoms and those who were current CTS cases (table 3).

Men and women were not evenly distributed in the initial physical workload categories. There was a higher percentage of men in high-force, low-repetition jobs $(84.1 \%)$, and women in low-force, high-repetition jobs

Table 3. Symptom severity, disability, and treatment for subjects with symptoms or carpal tunnel syndrome (CTS) cases dominant hand.

\begin{tabular}{|c|c|c|c|c|c|}
\hline & \multicolumn{2}{|c|}{$\begin{array}{l}\text { Past or current } \\
\text { symptoms }(\mathrm{N}=17)\end{array}$} & \multicolumn{2}{|c|}{$\begin{array}{l}\text { CTS cases } \\
(\mathrm{N}=45)\end{array}$} & \multirow[t]{2}{*}{ P-value a } \\
\hline & Mean & $\%$ & Mean & $\%$ & \\
\hline $\begin{array}{l}\text { Severity score } \\
\text { on hand-wrist symptom } \\
\text { in past } 7 \text {-days }{ }^{b}\end{array}$ & 3.0 & . & 2.7 & . & 0.20 \\
\hline QuickDASH score ${ }^{b}$ & 23.0 & . & 22.5 & . & 0.88 \\
\hline $\begin{array}{l}\text { Symptoms interfere } \\
\text { with work pace or quality }\end{array}$ & . & 23.5 & . & 22.7 & 0.95 \\
\hline $\begin{array}{l}\text { Days lost work } \\
\text { due to symptoms (median) }\end{array}$ & 1.8 & . & 1.9 & . & 0.29 \\
\hline Hand-wrist treatment type & & & & & \\
\hline Injection/medication & . & 0 & . & 2.2 & \\
\hline Massage & . & 0 & . & 4.4 & \\
\hline Massage/medication & . & 0 & . & 4.4 & \\
\hline Medication & . & 5.9 & . & 15.6 & \\
\hline Medication/other & . & 0 & . & 2.2 & \\
\hline Medication/physical therapy & . & 0 & . & 2.2 & \\
\hline Physical therapy & . & 11.8 & . & 0 & \\
\hline Other & . & 5.9 & . & 2.2 & \\
\hline Had hand surgery & . & 0 & . & 9.1 & . \\
\hline
\end{tabular}

a Chi-squared or Fisher's tests, Wilcoxon test, or Student's t-test, $\alpha=0.05$. b Symptom severity and QuickDASH was obtained for those with handwrist symptoms in last 7-days only: $\mathrm{N}=14$ for current symptoms and $\mathrm{N}=45$ for $\mathrm{CTS}$ cases
$(57.7 \%, \mathrm{P}=0.003)$. No significant difference in original job categories was observed among the CTS cases compared to the rest of the study population $(\mathrm{P}=0.61)$. At baseline (table 4), the four CTS status groups showed differences with respect to the presence of any hand-arm vibration exposure $(\mathrm{P}=0.039)$, percent time with a forceful power grip $(\mathrm{P}=0.035)$, and percent time with wrist flexion or extension $>45^{\circ}(\mathrm{P}=0.026)$. The group with CTS showed the highest proportion of subjects exposed to hand-arm vibration and forceful power grip but the second lowest proportion of subjects exposed to wrist flexion or extension $>45^{\circ}$.

A significantly higher proportion of dominant-hand CTS cases and those with past or current symptoms reported high job demands whereas those with neither current symptoms nor positive NCV results had significantly greater job satisfaction. As expected, a significantly lower proportion of CTS cases reported having high general good health but there were no significant differences in SF-12 scores (table 5).

\section{Natural course of hand-wrist symptoms and CTS}

Among the baseline population ( $\mathrm{N}=691), 15.1 \%$ on the dominant side and $11.4 \%$ on the non-dominant side had CTS symptoms at baseline. Among the baseline population available at one-year follow-up $(\mathrm{N}=418)$, the prevalence of baseline symptoms $(14.1 \%$ and $11.0 \%$ respectively) was similar to the larger baseline population $(\mathrm{N}=691,15.1 \%$ on the dominant and $11.4 \%$ on the non-dominant side, respectively). The prevalence at oneyear follow-up ( $\mathrm{N}=418)$ was $12.9 \%$ and $12.3 \%$, respectively. Prevalence of CTS cases was only slightly lower on the dominant side but almost half that of the baseline on the non-dominant side. Incidence of symptoms at 12 months was slightly lower than prevalence on the dominant side but higher on the non-dominant side.

There were only five subjects, who had neither symptoms nor positive NCV results at baseline, who became incident cases by follow-up, one on the dominant and four on the non-dominant side (table 6). Asymptomatic subjects who had positive NCV results at baseline as well as symptomatic subjects with negative NCV results were much more likely to become CTS cases than those with neither symptoms nor abnormal NCV findings. Persistence of symptoms for $\geq 1$ per week in the previous year with positive NCV results at baseline was $44.4 \%$ on the dominant and $52.0 \%$ on the non-dominant side. Of those with CTS at baseline, virtually no one recovered by the one-year follow-up. This suggests that among active workers with CTS, the condition is unlikely to go away in one year without some sort of job improvement or medical intervention.

The major pathway for the other four categories was toward becoming a CTS case. Incident cases were 
Table 4. Observed exposures by dominant-hand status at baseline $(\mathrm{N}=418)$. Cut-off points close to $75^{\text {th }}$ percentile. [NCV=nerve conduction velocity; CTS=carpal tunnel syndrome.]

\begin{tabular}{|c|c|c|c|c|c|c|}
\hline Percent higher level & $\begin{array}{l}\text { Il subjects attending } \\
\text { one year follow-up } \\
\qquad(\mathrm{N}=418)\end{array}$ & $\begin{array}{l}\text { g No symptoms } \\
\text { and negative NCV } \\
(\mathrm{N}=191)\end{array}$ & $\begin{array}{c}\text { No symptoms } \\
\text { and positive NCV } \\
(\mathrm{N}=165)\end{array}$ & $\begin{array}{l}\text { Past or current } \\
\text { symptoms } \\
(\mathrm{N}=17)\end{array}$ & $\begin{array}{l}\text { CTS cases } \\
(\mathrm{N}=45)\end{array}$ & $\mathrm{P}$-value a \\
\hline Frequency of forceful exertions ${ }^{b}$ ( $\geq 5$ times/min) & 23.9 & 22.5 & 24.8 & 23.5 & 26.7 & 0.92 \\
\hline Duty cycle of forceful exertions ${ }^{b}$ ( $\geq 20 \%$ time) & 29.4 & 25.7 & 32.1 & 35.3 & 33.3 & 0.48 \\
\hline Vibration (yes) & 12.4 & 9.4 & 13.3 & 5.9 & 24.4 & 0.039 \\
\hline Hand activity level (HAL) & 14.8 & 13.1 & 15.2 & 35.3 & 13.3 & 0.10 \\
\hline High power grip ( $\geq 1 \%$ time) & 28.7 & 22.5 & 31.5 & 35.3 & 42.2 & 0.035 \\
\hline High pinch grip ( $\geq 5 \%$ time) & 22.0 & 18.3 & 26.1 & 11.8 & 26.7 & 0.20 \\
\hline High lifting force ( $\geq 15 \%$ time) & 21.1 & 19.9 & 23.0 & 17.6 & 20.0 & 0.88 \\
\hline Wrist flexion or extension $\geq 15^{\circ}$ ( $\geq 50 \%$ time) & 32.8 & 34.0 & 31.5 & 35.3 & 31.1 & 0.95 \\
\hline Wrist flexion $\geq 15^{\circ}$ or extension $\geq 45^{\circ}$ ( $\geq 20 \%$ time $)$ & 33.5 & 32.5 & 33.3 & 35.3 & 37.8 & 0.92 \\
\hline Wrist flexion or extension $\geq 45^{\circ}$ ( $\geq 3 \%$ time) & 28.2 & 29.8 & 32.1 & 5.9 & 15.6 & 0.026 \\
\hline $\begin{array}{l}\text { Wrist radial deviation }<5^{\circ} \text { or } \\
\text { ulnar deviation } \geq 10^{\circ}(\geq 25 \% \text { time })\end{array}$ & 26.1 & 24.1 & 29.7 & 5.9 & 28.9 & 0.15 \\
\hline $\begin{array}{l}\text { Wrist radial deviation }<5^{\circ} \\
\left.\text { or ulnar deviation } \geq 20^{\circ} \text { ( } \geq 8 \% \text { time }\right)\end{array}$ & 23.9 & 23.6 & 24.2 & 11.8 & 28.9 & 0.57 \\
\hline
\end{tabular}

a Chi-Squared or Fisher's exact test for the four-hand status groups, $\alpha=0.05$.

${ }^{\mathrm{b}}$ Forceful exertions were defined as $\geq 8.9 \mathrm{~N}$ of pinch force or object weight (corresponding to $2 \mathrm{lb}$ or $0.9 \mathrm{~kg}$ ), or $44.1 \mathrm{~N}$ of power grip, object weight (corresponding to $10 \mathrm{lb}$ or $4.5 \mathrm{~kg}$ ) according to the Washington State ergonomics guidelines (15).

Table 5. Psychosocial aspects of work at baseline for the subjects by dominant-hand status. [NCV=nerve conduction velocity; CTS=carpal tunnel syndrome; SF-12=standard form 12]

\begin{tabular}{|c|c|c|c|c|c|c|c|c|c|c|c|c|c|c|c|c|}
\hline \multirow[t]{2}{*}{ Characteristic } & \multicolumn{3}{|c|}{$\begin{array}{l}\text { All subjects attending } \\
\text { one year follow-up } \\
(\mathrm{N}=400)^{\text {a }}\end{array}$} & \multicolumn{3}{|c|}{$\begin{array}{c}\text { No symptoms } \\
\text { and negative NCV } \\
(\mathrm{N}=185)^{\mathrm{a}}\end{array}$} & \multicolumn{3}{|c|}{$\begin{array}{c}\text { No symptoms } \\
\text { and positive NCV } \\
(\mathrm{N}=156)^{\mathrm{a}}\end{array}$} & \multicolumn{3}{|c|}{$\begin{array}{l}\text { Past or current } \\
\text { symptoms } \\
(\mathrm{N}=16)^{\mathrm{a}}\end{array}$} & \multicolumn{3}{|c|}{$\begin{array}{l}\text { CTS cases } \\
(\mathrm{N}=43)^{\mathrm{a}}\end{array}$} & \multirow[t]{2}{*}{$P$-value } \\
\hline & $\%$ & Median & Range & $\%$ & Median & Range & $\%$ & Median & Range & $\%$ & Median & Range & $\%$ & Median & Range & \\
\hline $\begin{array}{l}\text { High job } \\
\text { demands }^{b}\end{array}$ & 63.8 & . & . & 63.2 & . & . & 58.3 & . & . & 87.5 & 5. & . & 76.7 & . & . & $0.027^{c}$ \\
\hline $\begin{array}{l}\text { High decision } \\
\text { latitude }\end{array}$ & 50.0 & . & . & 55.7 & . & . & 45.5 & . & . & 43.8 & 8. & . & 44.2 & . & . & $0.21^{\mathrm{c}}$ \\
\hline $\begin{array}{l}\text { High job } \\
\text { satisfaction }\end{array}$ & 69.8 & . & . & 76.8 & . & . & 64.7 & . & . & 56.2 & 2. & . & 62.8 & . & . & $0.036^{c}$ \\
\hline $\begin{array}{l}\text { High social } \\
\text { support }\end{array}$ & 51.0 & . & . & 50.8 & . & . & 50.0 & . & . & 56.3 & 3. & . & 53.5 & . & . & $0.95 c$ \\
\hline $\begin{array}{l}\text { High job } \\
\text { security }\end{array}$ & 68.8 & . & . & 74.1 & . & $\cdot$ & 64.7 & . & . & 62.5 & 5. & . & 62.8 & . & . & $0.20^{c}$ \\
\hline $\begin{array}{l}\text { High general } \\
\text { health }\end{array}$ & 54.5 & . & . & 57.3 & . & . & 57.1 & . & . & 62.5 & 5. & . & 30.2 & . & . & $0.009 c$ \\
\hline Health SF-12 b & & & & & & & & & & & & & & & & \\
\hline $\begin{array}{l}\text { Physical } \\
\text { Mental }\end{array}$ & . & $\begin{array}{l}48.5 \\
52.3\end{array}$ & $\begin{array}{l}20.2-61.8 \\
17.0-63.4\end{array}$ & . & $\begin{array}{l}48.5 \\
51.8\end{array}$ & $\begin{array}{l}26.3-61.8 \\
17.0-62.7\end{array}$ & . & $\begin{array}{l}48.8 \\
53.2\end{array}$ & $\begin{array}{l}20.8-58.0 \\
18.9-63.4\end{array}$ & $\cdot$ & $\begin{array}{l}46.7 \\
50.9\end{array}$ & $\begin{array}{l}20.2-55.6 \\
26.5-57.9\end{array}$ & . & $\begin{array}{l}46.8 \\
52.1\end{array}$ & $\begin{array}{l}30.3-56.9 \\
21.6-62.0\end{array}$ & $\begin{array}{l}0.66^{d} \\
0.36^{d}\end{array}$ \\
\hline
\end{tabular}

a For health factors SF-12 (physical and mental), the number of subjects differed ( $N=358,173,135,15$ and 35, respectively)

b Psychosocial factors were dichotomized based on median score: job demands (median 3.0, range -4.0-10.0), decision latitude (median 10.0, range $-2.0-22.0$ ), social support (median 9.0, range 3.0-12.0), job satisfaction (median 1.0, range -3.0-3.0), job security (median 1.0, range $-3.0-3.0$ ), and general health (median 7.0 , range $2.0-10.0$ )

${ }^{c}$ Chi-squared or Fisher's exact test, $\alpha=0.05$

${ }^{\mathrm{d}}$ Kruskal-Wallis test, $\alpha=0.05$ 
Table 6. Prevalence and incidence of carpal tunnel syndrome (CTS) cases and symptoms. [NCV=nerve conduction velocity]

\begin{tabular}{|c|c|c|c|c|}
\hline \multirow[t]{2}{*}{ Health outcome } & \multicolumn{2}{|c|}{$\begin{array}{l}\text { Dominant } \\
\text { hand (D) }\end{array}$} & \multicolumn{2}{|c|}{$\begin{array}{l}\text { Non-dominant } \\
\text { and (ND) }\end{array}$} \\
\hline & N & $\%$ & $\mathrm{~N}$ & $\%$ \\
\hline \multicolumn{5}{|l|}{$\begin{array}{l}\text { Prevalence of hand symptoms } \\
\text { during the past } 12 \text { months a }\end{array}$} \\
\hline $\begin{array}{l}\text { Total baseline population ( } \mathrm{N}=691) \\
\text { Those of the baseline population } \\
\text { who attended follow-up, } \\
\text { baseline value }(\mathrm{N}=418) \\
\text { One-year follow-up }(\mathrm{N}=418)\end{array}$ & $\begin{array}{l}62 \\
58\end{array}$ & $\begin{array}{l}14.8 \\
13.9\end{array}$ & $\begin{array}{l}53 \\
62\end{array}$ & $\begin{array}{l}12.7 \\
14.8\end{array}$ \\
\hline \multicolumn{5}{|l|}{ Prevalence of carpal tunnel syndrome ${ }^{b}$} \\
\hline $\begin{array}{l}\text { Total baseline population ( } \mathrm{N}=691) \\
\text { Those of the baseline population } \\
\text { who attended follow-up, } \\
\text { baseline value }(\mathrm{N}=418) \\
\text { One-year follow-up }(\mathrm{N}=418)\end{array}$ & $\begin{array}{l}45 \\
48\end{array}$ & $\begin{array}{l}10.8 \\
11.5\end{array}$ & $\begin{array}{l}25 \\
35\end{array}$ & $\begin{array}{l}6.0 \\
8.4\end{array}$ \\
\hline $\begin{array}{l}\text { Incidence of symptoms at } \\
12 \text { months [N=191+165=356 (D), } \\
288+77=365 \text { (ND)] }\end{array}$ & 30 & 8.4 & 38 & 10.4 \\
\hline $\begin{array}{l}\text { One-year incidence of CTS } \\
\text { cases }[N=418-45=373 \text { (D), } \\
418-25=393(N D)]\end{array}$ & 28 & 7.5 & 25 & 6.4 \\
\hline $\begin{array}{l}\text { No symptoms and negative NCV } \\
{[\mathrm{N}=191 \text { (D), } 288 \text { (ND)] }}\end{array}$ & 1 & 0.5 & 4 & 1.4 \\
\hline $\begin{array}{l}\text { No symptoms but positive NCV } \\
{[\mathrm{N}=165 \text { (D), } 77 \text { (ND)] }} \\
\text { Symptoms but negative NCV }\end{array}$ & 23 & 13.9 & 15 & 19.5 \\
\hline at baseline [N=14 (D), 21 (ND)] & 3 & 21.4 & 2 & 9.5 \\
\hline $\begin{array}{l}\text { Persistence of symptoms } \\
\text { at } 12 \text { months }[N=3+14+45=62(D) \text {, } \\
7+21+25=53(N D)]^{c}\end{array}$ & 28 & 45.2 & 24 & 45.3 \\
\hline $\begin{array}{l}\text { Persistence of CTS cases } \\
{[N=45 \text { (D), } 25 \text { (ND)] }}\end{array}$ & 20 & 44.4 & 13 & 52.0 \\
\hline $\begin{array}{l}\text { Complete recovery from CTS cases } \\
\text { [N=45 (D), } 25 \text { (ND)] }\end{array}$ & 2 & 4.4 & 0 & 0 \\
\hline
\end{tabular}

a Denotes burning, numbness, tingling, or pain of $\geq 1$ of 1-3 digits with a frequency of $\geq 1$ per month or lasting $\geq 1$ week and not a traumatic onset. b Criteria for symptoms as above and a positive sign of the NCV test (22).

c May include recurrence of symptoms or CTS cases.

present across the sites, both in manufacturing and healthcare. The incidence of CTS cases tended to be slightly higher on the dominant side. Those with either symptoms or positive NCV results at baseline were much more likely to become a CTS case within one year than those with neither symptoms nor positive NCV results. Persistence of CTS at one year was high for both the dominant (44.4\%) and non-dominant (52.0\%) hands, with virtually no complete recovery from CTS case status by one year.

There was some concern that having CTS in one wrist might predispose the worker to developing CTS in the other wrist as he or she tries to protect the damaged wrist by overcompensating with the other hand. However, of those 28 subjects who developed dominant-side incident case status, two (7\%) had CTS in the non-dominant hand at baseline. Of the 21 non-dominant hand incident cases, three $(14.3 \%)$ were CTS cases on the dominant side at baseline.

\section{Job changes between baseline and follow-up}

Of the 153 subjects who had neither symptoms nor positive NCV findings on the dominant side throughout the study, $12.4 \%(\mathrm{~N}=19)$ reported a job change that was confirmed by a study ergonomist during the follow-up. However, based on ergonomist assessment, there was no consistent pattern in the change of job physical load category.

Interference with quality or pace of work, sick leave, and seeking medical advice

Of the 28 CTS incident cases, $6(21.4 \%)$ at baseline and $5(17.9 \%)$ at follow-up reported difficulty in maintaining their normal pace or quality of work, and $28.6 \%$ reported that they had sought medical treatment at follow-up. Among persistent cases at follow-up, 30\% reported interference with the pace or quality of work, and $25 \%$ reported seeking medical treatment.

\section{Discussion}

This descriptive paper followed the natural course of CTS and associated symptoms in a working population in manufacturing and healthcare industries with different physical and psychosocial risk factors. In addition to detailed questionnaires and electrodiagnostic testing, many of the individual job physical exposures - rather than being estimated by the workers or ergonomists - were observed and systematically video-recorded by ergonomists, who quantified the analysis frame-byframe in the laboratory. The vast majority of the subjects remained with neither positive NCV test results nor symptoms of CTS. However, the one-year incidence was at least double that reported in the general population or from workers compensation claims incidence data. Also persistence or recurrence of CTS case status at one year follow-up was high. CTS case status at baseline was associated with exposure to hand-arm vibration, exertion of high hand force in power grip, and wrist flexion or extension of $>45^{\circ}$ as well as high job demands, job satisfaction, and perceived general health. Vibrating tool use and forceful power grip may be correlated. Although we looked at hand activity level (11), we did not see significant differences between the groups nor did we observe a significant association between hand activity level and CTS in our cross-sectional logistic regression analysis. However, we did see a significant relationship between hand force and CTS in the crosssectional analysis (15). 
As this study shows, case definitions are critical in estimating both incidence and prevalence of work-related MSD, particularly CTS. In an effort to identify "nontrivial" hand-wrist cases and increase the likelihood of subjects remembering if they had had an episode in the previous year, we limited the case definition to those with recurring symptoms of non-traumatic origin. The definition of a CTS case in this study is consistent with the criteria used for accepting a workers compensation case (similar NCV criteria) in Washington State. However, because our "CTS cases" were still working with symptoms and positive NCV tests, they may be more representative of milder CTS than other CTS case series based on surgical or workers' compensation cases. This study suggests that both symptoms and NCV test status may predict future CTS. In an 11-year follow-up study of CTS in an industrial population, Nathan et al (20) reported an increase in the prevalence of median nerve slowing but not symptoms or CTS case status over time. Similar to our study (although using different methods for CTS case ascertainment and NCV measurements), symptoms were more frequently reported by women than men but sensory latencies were originally slightly lower among women at baseline and slightly higher at follow-up (not statistically significant). Nathan et al concluded that median nerve slowing increases with age but symptoms do not. For surveillance purposes, monitoring symptoms of workers rather than NCV results may be more important.

Two important limitations of our study were the participation and follow-up rates $(64.5 \%$ and $62.5 \%$, respectively). The production process posed the great- est restriction on participation in our study. While some supervisors actively encouraged participation, many others were more concerned about meeting production needs and discouraged participation. It was extremely difficult to identify the actual number of potentially eligible subjects. For some sites, we were limited in the total number of subjects that we could include in the study. The second restriction on participation was the economic recession experienced during the study. It is difficult to estimate how the baseline and follow-up participation rates affected our estimates of prevalence, incidence, and persistence of hand-wrist problems. However, the reasons for non-participation and nonretention appeared to be mostly production-related and due to the economic recession. Moreover, our data showed that the proportion of those lost to follow-up was greatest for those with no symptoms at baseline (figure 1), ie, we saw no clear health-based selection out of our cohort. More likely, loss to follow-up was due to those with less seniority being laid off first (data not shown). Limiting subject selection to those with $\geq 4$ tasks may have eliminated those with infrequent but high hand-wrist loads such as mechanics or other skilled trades people, thereby underestimating the effect of high physical loads.

The one year incidence of new symptoms on the dominant (8.4\%) and non-dominant side (10.4\%) were high compared to the population prevalence studies of Atroshi (18). Those with symptoms at baseline were at a high risk of developing CTS case status at follow-up, which is in line with the results of a French study (22, 26). Symptoms and job changes were collected every

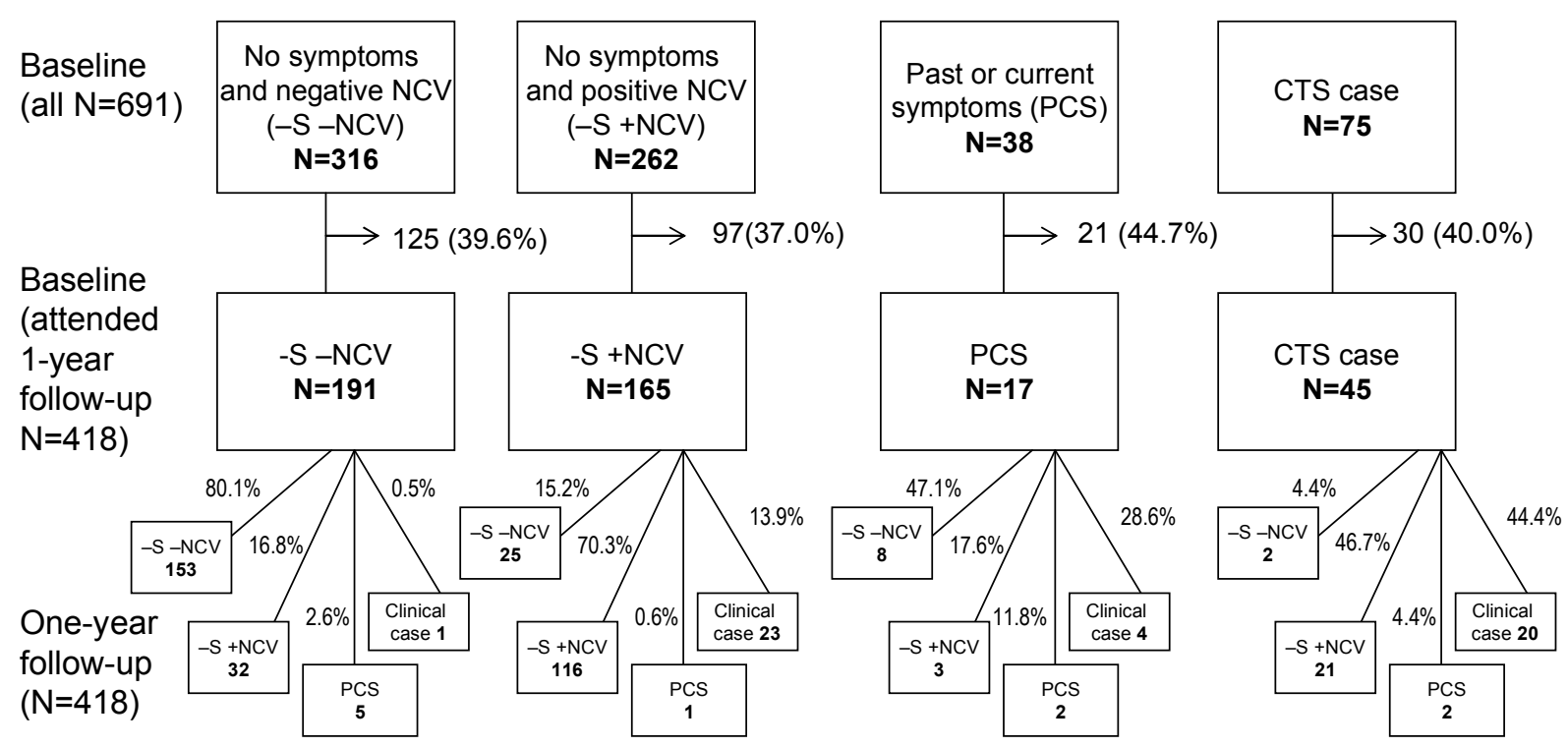

Figure 1. Natural course of carpal tunnel syndrome (CTS) and associated symptoms - dominant hand. [NCV=nerve velocity conduction] 
4 months while NCV data were collected annually. Job changes were frequent, but exposure levels remained largely similar to those at baseline.

There was some concern that having CTS in one wrist might predispose the worker to developing CTS in the other wrist as the worker tried to overcompensate with the other hand. However, of those 28 subjects who developed dominant-side incident case status, 2 (7\%) had CTS in the non-dominant hand at baseline. Of the 21 non-dominant hand incident cases, $3(14.3 \%)$ were CTS cases on the dominant side at baseline. Those subjects with only symptoms or positive NCV results at baseline were much more likely to develop CTS case status within one year than those with neither reported symptoms nor findings. Those with positive NCV findings at baseline were 3.6 times more likely to be CTS cases at follow-up, and $28.6 \%$ of those with CTS symptoms at baseline were CTS cases by follow-up, although the number of new cases was small. These results indicate that surveillance of symptoms among working populations may identify subgroups with a high risk of becoming CTS cases (secondary prevention). The change from having current or past symptoms to becoming a CTS case status $(28.6 \%)$ was more likely than from having a positive NCV result alone (14\%). Persistence of symptoms and CTS at one year was high while complete recovery from being a CTS case was very low $(4.4 \%$ on the dominant and $0 \%$ on the non-dominant side). This is quite different from our experience with rotator cuff syndrome cases in the same population where $40.6 \%$ had recovered within one year (23). A large proportion of CTS cases at baseline were asymptomatic at follow-up (47\%) but still had abnormal NCV findings.

At one-year follow-up, both incident (28.6\%) and persistent $(25 \%)$ cases reported having sought treatment while $17.9 \%$ and $30 \%$, respectively, reported their problem interfered with the pace or quality of work. However, only one incident case reported missing work, and $10.7 \%$ of incident and $5 \%$ of recurring/persistent cases reported moving to light duty. The relatively high prevalence of reporting interference with work pace or quality due to CTS symptoms is consistent with the findings of Stewart et al (24) with respect to US workers with musculoskeletal pain reporting $>5$ hours of lost or reduced productivity per week in the previous 2 weeks. The vast majority reported reduced performance while at work rather than work absence. This may be related to concerns about job loss or transfer.

Both CTS cases and the subjects with current symptoms had higher perceived job demands while only symptomatic cases had lower job satisfaction (table 5). However, the most striking difference was the low proportion of CTS cases that reported good general health. This was particularly interesting because there was no difference between groups with respect to SF-12 scores.
Reported job changes were common and as frequent among those who were non-symptomatic and without physical findings throughout the study as among the incident cases. The small number of subjects with CTS case status at any time prevented a detailed analysis of the relations between the direction of change in physical loading and the change in diagnostic group. It therefore remains unknown whether the frequent job changes in this population represented an informal way to reduce specific exposures believed to play a role in CTS.

In working populations, symptoms associated with CTS appear to be frequent and volatile in their course. Those with symptoms or positive NCV results alone at baseline appear more likely to become CTS cases by one year. The comparable proportion of those reporting that symptoms interfere with work quality among those with persistent symptoms and CTS cases suggests that self-reported symptoms should not be ignored. To better understand the clinical course in working populations, it is imperative that case definitions include specific information on the location of symptoms, some estimate of duration and frequency of episodes, and standardized clinical tests. In a follow-up study, changes in both exposure and health outcome need to be monitored. For example, by identifying all jobs with frequent high hand force, efforts should be made to reduce the exposure (primary prevention). For those who are symptomatic or have positive NCV findings, efforts should be made to reduce exposure through job modification and monitor these workers closely to prevent further progress of the disorder (secondary prevention). Frequent follow-up will identify incident cases that may be missed with annual follow-up alone. The fact that we were able to observe changes in health status as well as persistence of CTS in a one-year period is quite important for primary and secondary prevention strategies. This is one of the first studies with a detailed exposure assessment at the individual level that is extremely labor intensive. Loss to follow-up would have increased dramatically by two years. As industrial environments are changing rapidly, it is difficult to assume exposures are constant over time. The fact that this study conducted detailed individual exposure assessments after a one-year interval increases the likelihood that we adequately captured significant changes in exposure for individuals.

\section{Acknowledgements}

We acknowledge the important contributions of Peregrin Spielholz and Ruby Irving in exposure assessment, Dana Wilcox, Sarah West, and Tiffany Ballard in health assessment, Mary Ellen Burris and Corinne Mansmith in nerve conduction testing, and Gary Franklin for his 
review of all the NCV findings. We also thank the workers and employers who made this research possible. This research was funded in part by the US National Institute for Occupational Safety and Health (OH007316) and the Washington State Department of Labor and Industries.

\section{References}

1. Levine DW, Simmons BP, Koris MJ, Daltroy LH, Hohl GG, Fossel $\mathrm{AH}$ et al. A self-administered questionnaire for the assessment of severity of symptoms and functional status in carpal tunnel syndrome. The Journal of Bone and Joint Surgery. 1993;75-A(11):1585-92.

2. Shiri R, Varonen H, Heliövaara, M Viikari-Juntura E. Hand dominance in upper extremity musculoskeletal disorders. $\mathrm{J}$ Rheumatol. 2007 May;34(5):1076-82.

3. Gelfman R, Melton Jr L, Yawn BP, Wollan PC, Amadio PC, Stevens JC. Long-term trends in carpal tunnel syndrome. Neurology. 2009;72(1):33-41.

4. Armstrong T, Dale AM, Franzblau A, Evanoff BA. Risk factors for carpal tunnel syndrome and median neuropathy in a working population. J Occup Environ Med. 2008;50(12):1355-64.

5. Bongers FJ, Schellevis FG, van den Bosch WJ, van der Zee J. Carpal tunnel syndrome in general practice (1987 and 2001): incidence and the role of occupational and non-occupational factors. Br J Gen Pract 2007;57(534):36-9.

6. Mondelli M, Giannini F, Giacchi M. Carpal tunnel syndrome incidence in a general population. Neurology. 2002;58(2):289-94.

7. Silverstein B, Adams D. Work-related musculoskeletal disorders of the neck, back, and upper extremity in Washington State: State fund and self-insured workers' compensation claims 1997-2005. In: Editor. editor, Series, Washington State, 2007.

8. Foley, M, Silverstein B, Polissar N. The economic burden of carpal tunnel syndrome: long-term earnings of CTS claimants in Washington State. Am J Ind Med. 2007;50(3):155-72.

9. van Rijn RM, Huisstede BM, Koes BW, Burdorf A. Associations between work-related factors and the carpal tunnel syndrome - a systematic review. Scand J Work Environ Health. 2009;35(1):19-36

10. ACGIH. Hand activity level. In: Editor. editor., Series, Cincinnati, Ohio: ACGIH, 1999.

11. Beaton DE, Wright DG, Katz JN, Upper Extremity Collaborative Group. Development of the QuickDASH: comparison of three item-reduction approaches. J Bone Joint Surg Am. 2005;87(5):1038-46

12. Ware Jr JE, Kosinski M, Keller SD. A 12-item short-form health survey. Construction of scales and preliminary tests of reliability and validity. Medical care. 1996;34(3):220-33.

13. Karasek R, Theorell T. The psychosocial work environment P 31-82 In: Karasek R, Theorell T (editors), Healthy Work: Stress, Productivity, and the Reconstruction of Working Life, New York: Basic Books, 1990.
14. Bigos, SJ, Battie MC, Spengler DM, Fisher LD, Fordyce WE, Hansson TH, et al. A prospective study of work perceptions and psychosocial factors affecting the report of back injury. Spine. 1991;16(1):1-8.

15. Sluiter JK, Rest KM, Frings-Dresen MH. Criteria document for evaluating the work-relatedness of upper-extremity musculoskeletal disorders. Scand J Work Environ Health. 2001; 27 Suppl 1:1-102.

16. Bao SS, Silverstein BA Howard N, Spielholz P. The Washington State SHARP approach to exposure assessment. In: Marras WS, Karwowski W (editors). The Occupational Ergonomics Handbook, Second Edition: Fundamentals and Assessment Tools for Occupational Ergonomics, New York: CRC Press; 2006, 44.1-.22.

17. Silverstein B, Fan ZJ, Smith CK, Bao SS, Howard N, Spielholz $\mathrm{P}$, et al. Gender adjustment or stratification in discerning upper extremity musculoskeletal disorder risk? Scand J Work Environ Health. 2009;35(2):113-26.

18. Yen, TY, Radwin RG. A video-based system for acquiring biomechanical data synchronized with arbitrary events and activities. IEEE Trans Biomed Eng. 1995;42(9):944-8.

19. Washington State Department of Labor and Industries, WISHA. Hazards zone job checklist. 2009. [Online] Available at http://www.lni.wa.gov/wisha/ergo/evaltools/ HazardZoneChecklist.pdf.

20. Nathan PA, Keniston RC, Myers D, Meadows KD, Lockwood RS. Natural history of median nerve sensory conduction in industry: relationship to symptoms and carpal tunnel syndrome in 558 hands over 11 years. Muscle \& Nerve 1998:711-721.

21. Atroshi I, Gummesson C, Johnsson R, Ornstein E, Ranstam J, Rosen I. Prevalence of carpal tunnel syndrome in a general population. JAMA. 1999; 282(2):153-8.

22. Descatha A, Chastang JF, Cyr D, Leclerc A, Roquelaure Y, Evanoff B. Do workers with self-reported symptoms have an elevated risk of developing upper extremity musculoskeletal disorders three years later? Occup Environ Med. 2008; 65(3):205-7.

23. Silverstein, BA, Viikari-Juntura E, Fan ZJ, Bonauto DK, Bao SS, Smith C. Natural course of nontraumatic rotator cuff tendinitis and shoulder symptoms in a working population. Scand J Work Environ Health. 2006;32(2):99-108.

24. Stewart, WF, Ricci JA, Chee E Morganstein D, Lipton R. Lost productive time and cost due to common pain conditions in the US workforce. JAMA. 2003;290(18):2443-54.

25. Washington State Department of Labor and Industries. Medical treatment guidelines. 2009. [Online] Available at www.lni. wa.gov/ClaimsIns/Files/OMD/CTSGuidelineFINAL.pdf.

26. Roquelaure $\mathrm{Y}$, Ha C, Laclerc A, Touranchet A, Sauteron M, Melchoir M, Embernon E, Goldberg M. Epidemiologic surveillance of upper extremity musculoskeletal disorders in a working population. Arthritis and Rheumatism 2006;55(5):765-78.

Received for publication: 3 December 2009 